\title{
Role of HLA-DP in the Presentation of Epitopes from the Truncated Bacterial PE38 Immunotoxin
}

\author{
Ronit Mazor, ${ }^{1}$ Selamawit Addissie, ${ }^{1}$ Youjin Jang, ${ }^{1}$ Chin-Hsien Tai, ${ }^{1}$ Jeremy Rose, ${ }^{2}$ Fran Hakim, ${ }^{2}$ and Ira Pastan ${ }^{1,3}$
}

Received 15 June 2016; accepted 18 August 2016; published online 27 October 2016

\begin{abstract}
Identification of helper T-cell epitopes is important in many fields of medicine. We previously used an experimental approach to identify T-cell epitopes in PE38, a truncated bacterial toxin used in immunotoxins. Here, we evaluated the ability of antibodies to DR, DP, or DQ to block T-cell responses to PE38 epitopes in 36 PBMC samples. We predicted the binding affinities of peptides to DR, DP, and DQ alleles using computational tools and analyzed their ability to predict the T-cell epitopes. We found that HLA-DR is responsible for $65 \%$ of the responses, DP $24 \%$, and DQ $4 \%$. One epitope that is presented in $20 \%$ of the samples (10/50) is entirely DP restricted and was not predicted to bind to DR or DP reference alleles using binding algorithms. We conclude that DP has an important role in helper T-cell response to PE38.
\end{abstract}

KEY WORDS: DP; epitope prediction; HLA class II; in silico; MHC class II; T-cell epitopes.

\section{INTRODUCTION}

Identification of helper T-cell epitopes is very important in several fields of medicine, which include vaccine development, allergy and autoimmunity, and immunogenicity of protein-based therapeutics. It is well established that presentation of peptide antigens by major histocompatibility complex (MHC) class II is a necessary though not sufficient step in helper T-cell activation and in mounting an effective and specific immune response (1).

HLA class II proteins are heterodimeric cell surface glycoproteins expressed on the membrane of professional antigen presenting cells (APCs). They consist of an alpha and beta chain encoded in one of three loci: HLA-DR, HLA-DP, and HLA-DQ (2). HLA class II molecules are extremely polymorphic with thousands of allelic variants, which affect the structure of their binding groove and, as a result, their binding specificity to peptides (3).

HLA binding prediction algorithms have been developed to calculate affinity of a specific peptide binding to a specific binding core. Such prediction algorithms were shown to be

\footnotetext{
${ }^{1}$ Laboratory of Molecular Biology, Center for Cancer Research, National Cancer Institute, National Institutes of Health, 37 Convent Drive, Room 5106, Bethesda, Maryland 20892-4264, USA.

${ }^{2}$ Experimental Transplantation and Immunology Branch, Center for Cancer Research, National Cancer Institute, National Institutes of Health, Bethesda, Maryland, USA.

${ }^{3}$ To whom correspondence should be addressed. (e-mail: pastani@mail.nih.gov)
}

productive in the identification of high affinity binders for vaccine therapies (4-7). While eliciting an immune response is desirable in the development of a vaccine, the development of antidrug antibodies to a protein therapeutic compromises the safety and efficacy of the drug product. Thus, these algorithms have been used to identify strong and promiscuous peptide binders. Then protein engineering can be used to construct mutant proteins that are poor binders and do not induce antibody responses (8-10).

T-cell epitope prediction using HLA binding prediction focuses mainly on DR molecules and rarely on DP or DQ (816). The focus on DR for immunogenicity management is not limited to the use of HLA binding algorithms; DP and DQ alleles are usually not considered in the assembly of representative human cohorts. Furthermore, recombinant or purified DP molecules or tetramers for functional and binding assays are uncommon. This trend is due, in part, to an assumption that DP molecules are less important for immune responses than DR (17) and because cell surface expression of DP and DQ was reported to be lower than that of DR (1820). Also in vitro stimulation of $\mathrm{T}$ cells was shown to induce DR expression in more T cells than DP and DQ (21). This lack of emphasis on DP and DQ alleles has resulted in smaller datasets, which affect the accuracy of predictions of peptide binding affinities for these alleles.

We previously sought to identify the T-cell epitopes in a truncated bacterial toxin PE38 that is used as the cytotoxic moiety in recombinant immunotoxins (RITs). These therapeutic proteins have high specificity and low toxicity and were shown to be highly effective in tumor eradication in 
hematological patients $(22,23)$. However, RITs are also very immunogenic due to the bacterial origin of the toxin and all patients formed neutralizing antibodies after one or two cycles of treatment (24). Using an experimental approach, we identified eight major epitopes (25) that were common on naive donors and previously treated patients; only four of these were predicted to bind at high affinity to multiple HLA molecules by commonly used HLA binding prediction programs (26). In addition, the programs predicted the presence of several high affinity binders that were not identified as epitopes in our experimental approach. A possible explanation for the DR binding analysis not predicting the binding of some epitopes is that some could be DP or DQ restricted. In this study, we examined the HLA class II restriction of the T-cell epitopes in PE38 and evaluated the effect of non-DR-restricted epitopes on successful identification by HLA binding algorithms. We found that DP has an important role in T-cell immunity to this protein and that this epitope is not predicted using DR, DP, or DQ binding prediction algorithms.

\section{MATERIALS AND METHODS}

\section{Human Donor PBMC Samples}

Peripheral blood mononuclear cells (PBMCs) from healthy volunteer donors at the National Institutes of Health $\left(\mathrm{NIH}^{3}\right)$ blood bank were collected under research protocols approved by the NIH Institutional Review Board (99-CC-0168) using apheresis. Also apheresis samples were obtained from patients treated with moxetumomab pasudotox or SS1P after informed consent in clinical trials (protocols 08-C-0026 and 06-CC-0150). A total of 36 PBMC samples were selected based on previously determined responses to PE38 peptides (25). Samples were qualified for the study if it demonstrated a response to one of the peptides described in Table I with all the following criteria: $\geq 85$ spot forming cells (SFC) $/ 10^{6}$ cells, $\geq 3$-fold the response in the no peptide control, and $\geq 3 \%$ of all SFC.

PBMCs were isolated and cryopreserved as previously described (27). Briefly, buffy coat was collected after FicollHypaque (GE Healthcare) density-gradient separation. Cells were washed three times with Dulbecco's phosphate buffered saline (PBS) without $\mathrm{Ca}$ and $\mathrm{Mg}$ and cryopreserved in liquid nitrogen at a concentration of $1-3 \times 10^{7}$ cells $/ \mathrm{ml}$ in RPMI media (Lonza) supplemented with $10 \%$ heat-inactivated human AB serum (Gemini) and 7.5\% DMSO (Cellgro).

\section{HLA Typing of PBMC Samples}

Genomic DNA was isolated from each PBMC sample using quick-gDNA MiniPrep (Zymo Research) and sent for HLA typing. $H L A-D R B$ genes were typed using polymerase chain reaction (PCR) sequence-specific-based tissue typing by the HLA typing unit at the NIH. HLA-DPB and HLA-DQB genes were typed by the Texas BioGene molecular typing laboratory.

\section{Peptide Synthesis}

All peptides were synthesized by American peptides with the exception of the CEFT peptide pool control
(Axxura). Peptides were purified to $>95 \%$ and were analyzed for homogeneity by HPLC. All custom peptide sequences are shown in Table I. Upon arrival, the peptides were resuspended in DMSO to a concentration of $2 \mathrm{mg} / \mathrm{ml}$. After resuspension, the peptide stocks were stored at $-20^{\circ} \mathrm{C}$. Peptides NNYGSTIEGLLD and PMDEPTLLYVLFEVF were designed to be used as a control that specifically binds to DQ and DP molecules based on a search of the Immune Epitope Database (www.iedb.org) (28-30).

\section{Specific In Vitro Expansion of PBMC}

PBMCs were expanded and stimulated as previously described $(27,31)$. Briefly, cells were thawed in assay media that contains RPMI, 5\% heat-inactivated AB serum, and P/S antibiotics. Cells were stimulated with $5 \mu \mathrm{g} / \mathrm{ml}$ of a PE38 containing immunotoxin (LMB-9) (32). On days 4, 7, and 10, cells were supplemented with fresh assay medium containing 20 units of interleukin 2 (IL-2) (Millipore). On day 14, cells were harvested, washed, and used for enzyme-linked immunoSpot (ELISpot) assays.

\section{HLA Restriction by ELISpot Assay}

White polyvinylidene fluoride (PVDF) filter plates (Mabtech) were coated with anti-IL-2 antibody (clone MT2A91/2C95 Mabtech) according to the manufacturer's protocol and incubated at $4{ }^{\circ} \mathrm{C}$ for $18 \mathrm{~h}$. Plates were washed with PBS and in vitro expanded cells were placed in a concentration of $1 \times 10^{5} /$ well. Next, the following inhibiting antibodies were added to the cells at a final concentration of $15 \mu \mathrm{g} / \mathrm{ml}$ : anti-DR (clone G45-6, BD), anti-DP (clone B7/21, Leinco), anti-DQ (clone SPVL3, Beckman Coulter), Pan class I (clone W6/32, BD), or combination of anti-DR, anti$\mathrm{DP}$, and anti-DQ antibodies. After $30 \mathrm{~min}$ incubation at $37^{\circ} \mathrm{C}$, PE38-derived peptides (listed in Table I) that were previously shown to activate the selected PBMC samples were added. Cells were incubated at $37^{\circ} \mathrm{C}$ for an additional $18 \mathrm{~h}$. Additional negative controls included cells with no peptide stimulation, cells with a peptide but no antibodies and in 5/36 samples, a negative control of an irrelevant peptide and antibodies that resulted in no T-cell response. Phytohemagglutinin (Sigma) was used as a technical positive control. The secretion of IL-2 following stimulation with peptides was detected using a secondary biotinylated anti-IL-2 antibody (clone MT8G10, Mabtech) followed with streptavidin, alkaline phosphatase conjugate (SA-ALP) (Mabtech), and nitro blue tetrazolium and 5-bromo-4-chloro-3'-indolyl phosphate (BCIP/NBT) substrate (KPL).

The ability of the anti-HLA antibodies to specifically inhibit DR, DP, or DQ presented T-cell activation was controlled by routinely stimulating specific samples using peptides with known restriction: CEFT (Axxura) for DR, NNYGSTIEGLLD for DQ, and a combination of TRHRQPRGWEQLEQC and PMDEPTLLYVLFEVF for DP to confirm the effectiveness of the inhibiting antibodies.

Spots were counted by computer-assisted image analysis (Immunospot 5.0; Cellular Technology Limited). Each assay was performed in quadruplicate and repeated at least twice. 
Table I. Peptides Used in the Study

\begin{tabular}{|c|c|c|c|c|}
\hline Peptide description & Amino acid sequence & Length & Origin & Ref \\
\hline Peptides $13-15$ & GYPVQRLVALYLAARLSWNQV & 21 & PE38 & This work \\
\hline Peptide 74 & PDARGRIRNGALLRV & 15 & PE38 & $(27)$ \\
\hline Peptide 75 & RGRIRNGALLRVYVP & 15 & PE38 & (27) \\
\hline Peptide 76 & IRNGALLRVYVPRSS & 15 & PE38 & (27) \\
\hline Peptide 77 & GALLRVYVPRSSLPG & 15 & PE38 & (27) \\
\hline Peptide 78 & LRVYVPRSSLPGFYR & 15 & PE38 & (27) \\
\hline Peptides 8-9 & TRHRQPRGWEQLEQCGYP & 18 & PE38 & This work \\
\hline Peptide 5 & ACHLPLETFTRHRQP & 15 & PE38 & $(27)$ \\
\hline Peptide 6 & LPLETFTRHRQPRGW & 15 & PE38 & (27) \\
\hline Peptide 67 & WRGFYIAGDPALAYG & 15 & PE38 & (27) \\
\hline Peptide 68 & FYIAGDPALAYGYAQ & 15 & PE38 & $(27)$ \\
\hline Peptide 93 & GPEEEGGRLETILGW & 15 & PE38 & (27) \\
\hline Peptide 94 & EEGGRLETILGWPLA & 15 & PE38 & (27) \\
\hline Peptide 95 & GRLETILGWPLAERT & 15 & PE38 & (27) \\
\hline Peptide 96 & ETILGWPLAERTVVI & 15 & PE38 & (27) \\
\hline Peptide 51 & TVERLLQAHRQLEER & 15 & PE38 & (27) \\
\hline Peptide 52 & RLLQAHRQLEERGYV & 15 & PE38 & (27) \\
\hline Peptide 56 & GYVFVGYHGTFLEAA & 15 & PE38 & (27) \\
\hline Peptide 57 & FVGYHGTFLEAAQSI & 15 & PE38 & (27) \\
\hline Peptide 58 & YHGTFLEAAQSIVFG & 15 & PE38 & (27) \\
\hline Peptide 59 & TFLEAAQSIVFGGVR & 15 & PE38 & $(27)$ \\
\hline DQ control & NNYGSTIEGLLD & 12 & Human herpesvirus 2 & $(28,29)$ \\
\hline DP control & PMDEPTLLYVLFEVF & 15 & Human mastadenovirus $\mathrm{C}$ & $(29,30)$ \\
\hline
\end{tabular}

\section{Determination of Restriction Element}

To determine the restricting element, the spots for each sample and epitope combinations were normalized; $0 \%$ represents no antibody control (no inhibition) and 100\% represents the combination of DR, DP, and DQ (maximal inhibition). Responses were considered restricted to a specific class II molecule if they exhibit a normalized inhibition of $\geq 70 \%$. Responses were considered to have co-presentation of two or three class II molecules if either more than one antibody was required for $\geq 70 \%$ inhibition or when more than one molecule had $\geq 70 \%$ inhibition. Assays that were not included in the restriction analysis include (1) signal in "no antibody" wells $<1.0 \times 10^{2}$ SFC, (2) signal in "no antibody" $<2$-fold background (no peptide control), and (3) three samples were excluded because the inhibition of all three class II together molecules was $<70 \%$ of the combination.

\section{Determination of DR, DP, and DQ Expression on PBMC Using Flow Cytometry}

PBMC, at $2 \times 10^{6}$ cells/tube, were blocked with mouse immunoglobulin $\mathrm{G}(\mathrm{IgG})$ for $10 \mathrm{~min}$, then stained with a panel of antibodies identifying lymphocyte and antigen presenting cell subsets that target the following cellular markers: BDCA1, BDCA2, CD56, CD14, CD3, CD4, CD8, and CD19 and HLA-DR, DP, or DQ or isotope controls (Supplementary Table S1). Cells were incubated for $20 \mathrm{~min}$ at $4^{\circ} \mathrm{C}$ in the dark, washed, and resuspended in fluorescence activated cell sorting (FACS) buffer (calcium- and magnesium-free HBSS with $0.2 \%$ BSA and $0.1 \% \quad \mathrm{NaN}_{3}$ ). Data were collected on a Gallios ${ }^{\mathrm{TM}}$ Flow Cytometer
(Beckman Coulter) and analyzed with FlowJo 9.6 (Treestar). The geometric mean fluorescence intensity of HLA antigens was determined for each cell population.

\section{Predicted Binding for HLA-DR, DP, and DQ Alleles}

The IEDB-recommended method (33) was used to predict the binding affinity of 24 PE38-derived peptides. The binding affinity to 15 HLA-DR alleles, 6 HLA-DP alleles, and 6 HLA-DQ alleles was submitted to the IEDB MHC-II binding predictions. The percentile rank of each peptide to each allele was recorded: the smaller the rank, the stronger the predicted binding. The binding threshold of $20 \%$ was imposed to calculate the number of alleles among the reference alleles that have predicted binding to each epitope peptide identified experimentally. A peptide was considered an epitope if it was predicted to bind to a third of the HLA molecules (i.e., $\geq 5 / 15$ for DR, $\geq 2 / 6$ for DP and DQ, and $\geq 9$ / 27 for all HLA class II combined). These criteria were previously shown to give the best correlation between HLADR prediction analysis and T-cell epitopes (26).

\section{RESULTS}

\section{HLA Restriction of T-Cell Responses to PE38-Derived Peptides}

We previously screened PBMC samples from 50 naive donors and 16 immunotoxin-treated patients and identified eight major T-cell epitopes in PE38 (25). To identify the class II subtype that is responsible for presentation of PE38derived antigenic peptides, we expanded some of those PBMC samples for 14 days with LMB-9 (a RIT containing 
PE38) and IL-2 and restimulated with peptides containing the cognate epitopes. The activation of T cells was assessed by IL2 ELISpot, and the restriction was determined by the ability of antibodies to HLA-DR, DP, or DQ to inhibit the response. Figure 1 shows representative responses of PBMC samples from four different donors.

Figure 1a shows a response that is entirely DR restricted. PBMCs were stimulated with peptides 13-15 that represent epitope 1. Cells that were not treated with inhibitory antibodies had a strong stimulation $\left(2.8 \times 10^{3} \mathrm{SFC} / 1 \times 10^{6}\right.$ cells); similarly, cells treated with anti-DP, DQ, or class I pan had a strong stimulation with a range of $2.2 \times 10^{3}-2.9 \times 10^{3}$ $\mathrm{SFC} / 1 \times 10^{6}$ cells, indicating that DP and DQ are not involved in the presentation of this peptide. However, cells that were incubated with antibodies against DR or a combination of antibodies against DR, DP, and DQ ("combo") had a significantly lower response than the cells with no antibody $\left(2.5 \times 10^{2}\right.$ and $1.5 \times 10^{2} \mathrm{SFC} / 1 \times 10^{6}$ cells, respectively) ( $p<0.05$ in the Mann-Whitney test). This result indicates that these PBMCs use DR molecules exclusively for the presentation of epitope 1.

Figure $1 b$ shows a response that is entirely DP restricted. PBMCs were stimulated with peptides 8-9 that represent epitope 3. Cells that were not treated with inhibitory antibodies had a strong stimulation $\left(9.7 \times 10^{2} \quad \mathrm{SFC} / 1 \times 10^{6}\right.$ cells); similarly, cells treated with anti-DR, DQ, or class I pan had a strong stimulation with a range of $8.6 \times 10^{2}-1.1 \times 10^{3}$ $\mathrm{SFC} / 1 \times 10^{6}$ cells, indicating that DR and DQ are not involved in the presentation of this peptide. However, cells that were incubated with antibodies against DP or a combination of the antibodies had a significantly lower response $(2.0 \times 10$ and $5.3 \times 10^{1} \mathrm{SFC} / 1 \times 10^{6}$ cells, respectively) $(p<0.05$ in the Mann-Whitney test). This result indicates that these PBMCs use DP molecules exclusively for the presentation of epitope 3.

Figure 1c shows a response that is entirely DQ restricted. PBMCs were stimulated with a combination of peptides 93 and 94 that represents epitope 6. Cells that were not treated with inhibitory antibodies had a strong stimulation $\left(8.8 \times 10^{2}\right.$ $\mathrm{SFC} / 1 \times 10^{6}$ cells); cells treated with anti-DR, DP, or class I pan also had a strong stimulation with a range of $7.3 \times 10^{2}-$ $9.2 \times 10^{2} \mathrm{SFC} / 1 \times 10^{6}$ cells, indicating that DR and DP are not involved in the presentation of this peptide. However, cells that were incubated with antibodies against DQ or a combination of antibodies against DR, DP, and DQ had a significantly lower response than the cells with no antibody $\left(6.4 \times 10\right.$ and $8.8 \times 10 \mathrm{SFC} / 1 \times 10^{6}$ cells, respectively $)(p<0.05$ in the Mann-Whitney test). This indicates that these PBMCs use DQ molecules exclusively for presentation of epitope 6 .

Figure 1d shows an example of co-presentation on DR, DP, and DQ. PBMCs were stimulated with peptides 13-15 that represent epitope 1 . Cells that were not treated with inhibitory antibodies had a strong stimulation $\left(8.2 \times 10^{2} \mathrm{SFC} / 1 \times 10^{6}\right.$ cells $)$; however, cells that were treated with either DR or DQ antibodies had a significantly lower response $(p<0.05$ in the Mann-Whitney test). While the combination of the three antibodies produced

\section{b}



Antibody

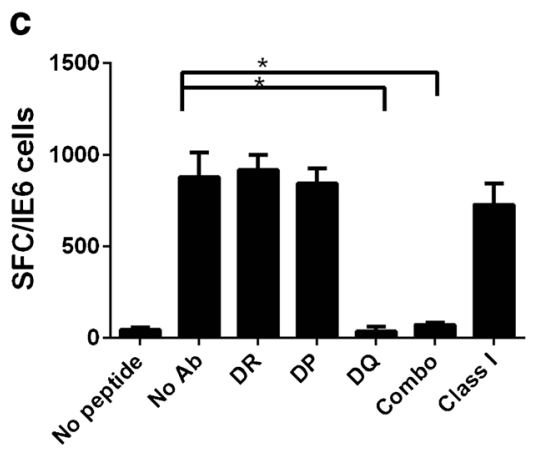

Antibody

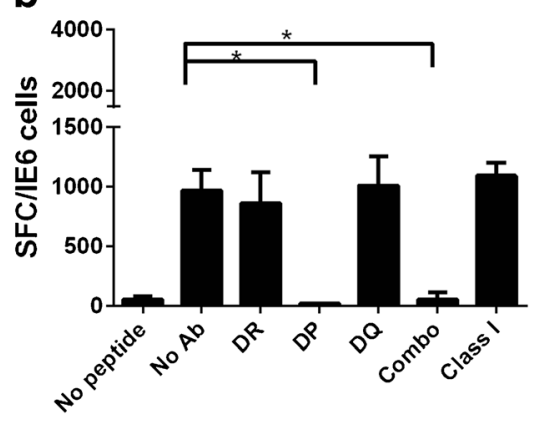

Antibody

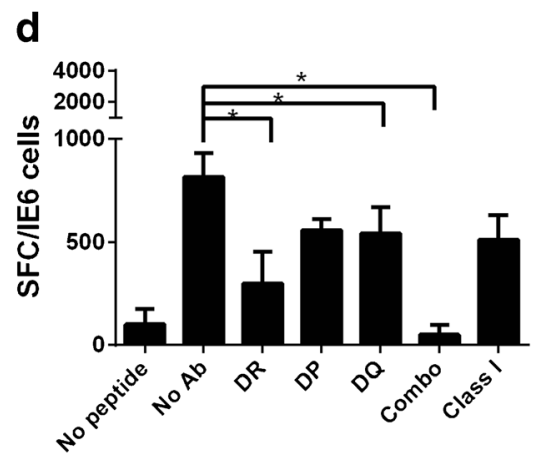

Antibody

Fig. 1. Representative inhibition pattern of antibodies against DR, DP, DQ, and class I pan in IL-2 ELISpot. PBMCs were stimulated with PE38 for 14 days and restimulated with various specific peptides that induce T-cell activation and IL-2 secretion. a PBMC stimulated with peptides $13-15$ and inhibited by DR antibody. b PBMC stimulated with peptides 8-9 and inhibited by DP antibody. c PBMC stimulated with peptides 93-94 and inhibited by DQ antibody. d PBMC stimulated with peptides 13-15 and partial inhibition by DR, DQ, and DP antibodies 
inhibition with a near background response of $5.0 \times 10 \mathrm{SFC} / 1 \times$ $10^{6}$, none of the individual antibodies was able to produce complete inhibition. Normalization of the inhibition between the "no antibody" (0\%) and "combination" (100\%) showed that the antibody against DR inhibits $66 \%$ of the response, DQ $34 \%$, and DP $31 \%$. The sum of the three responses (inhibition by anti-DR, anti-DP, or anti-DQ) is not necessarily expected to be precisely $100 \%$ because the responses were normalized to the combo control wells that included all three antibodies together.

\section{Epitope Restriction Analysis}

We used the antibody inhibition approach to analyze the restriction of peptides from all eight epitopes. To do this, we analyzed 54 PBMC/epitope combinations. Three responses were excluded because the cumulative inhibition of the three class II molecules was $<70 \%$. The results for the remaining 51 samples are summarized in Fig. 2 and described below. In order to determine HLA class II subtype restriction, only the PBMCs from donors that responded to a particular epitope were used for that epitope.

To identify the restriction to epitope 1 , PBMC samples were stimulated with a 21 mer peptide spanning amino acids 288-308 in PE38 (peptides 13-15) (Supplementary Table S1). Epitope 1 was significantly restricted by DR ( $p=0.0001$ in the Friedman test with Dunn's multiple comparisons) with a median of $91 \%$ inhibition (Fig. 2a). One PBMC sample showed co-presentation of this epitope with $66 \%$ inhibition by DR, $34 \%$ by DQ, and $31 \%$ by DP.

Epitope 2 is a complex epitope because the responses to this epitope spread over five overlapping peptides (peptides 74-78), which indicate more than a single 9 mer core. We previously divided this epitope into two subepitopes: epitope 2A spans peptides 74-76 and epitope 2B spans peptides 7678. To identify the restriction to epitope $2 \mathrm{~A}$, six $\mathrm{PBMC}$ samples were stimulated with peptides 74,75 , and 76 . We found that $4 / 6$ donors that responded to epitope $2 \mathrm{~A}$ were restricted by DP with a median of $86 \%$ inhibition and $2 / 6$ were restricted to DR (Fig. 2b). To identify the restriction to epitope 2B, five PBMC samples were stimulated with peptides 77 and 78; four of those samples were unique and one sample was also included in the analysis shown in $2 \mathrm{~A}$ because this donor responded similarly to peptides in $2 \mathrm{~A}$ and $2 \mathrm{~B}$. We found that $4 / 5$ donors that responded to epitope $2 \mathrm{~B}$ were presented by DR with a median inhibition of $78 \%$ (Fig. 2c). The sample that was common with $2 \mathrm{~A}$ was presented by DP. This result corroborates the complexity of this epitope and demonstrates that PBMCs from different individuals can present an epitope with different class II presentation molecules.

To identify the restriction to epitope 3, eight PBMC samples were stimulated with an 18 mer peptide spanning amino acids of
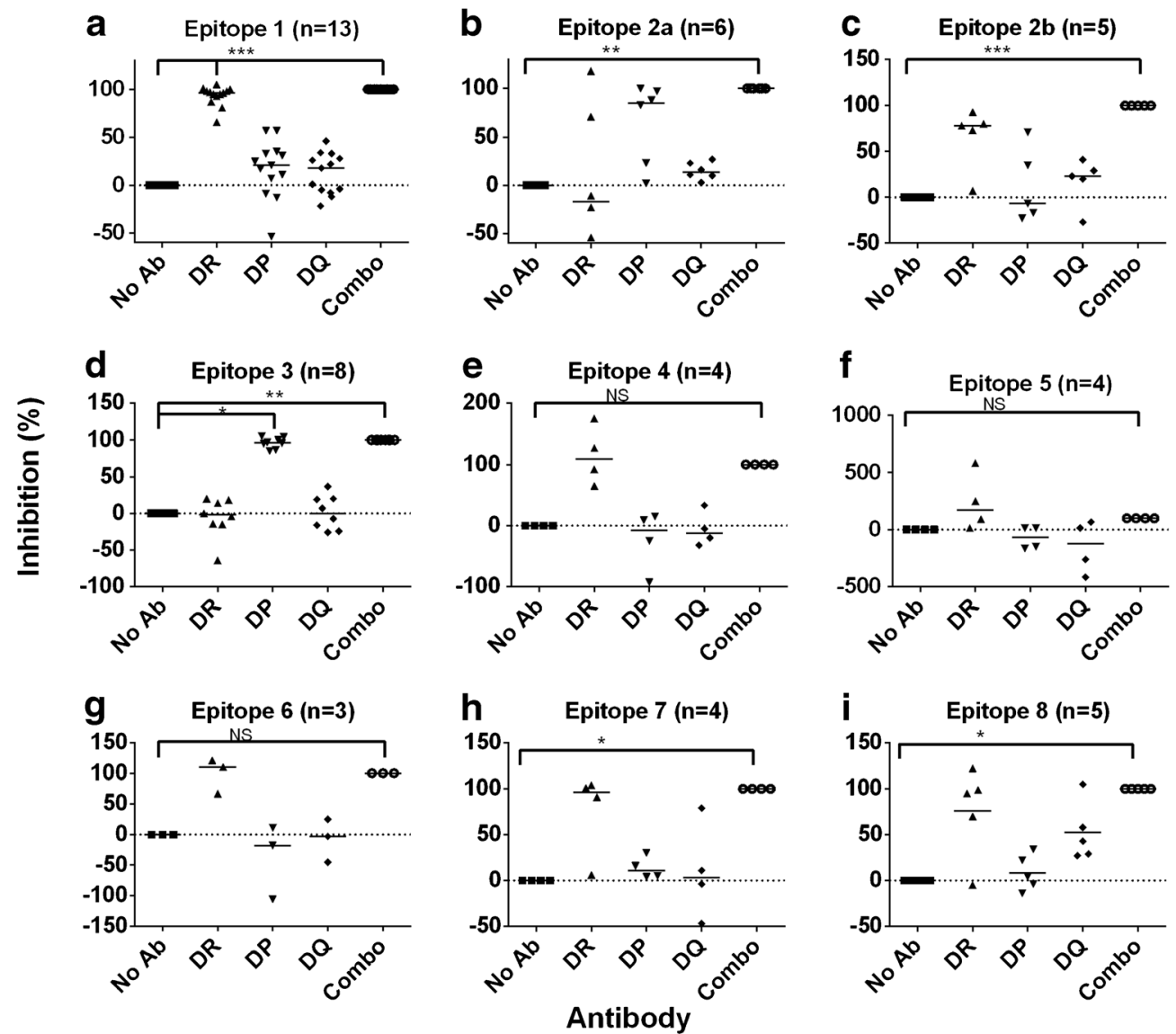

Fig. 2. Inhibition of T-cell responses to PE38-derived epitopes. a Epitope 1, peptides $13-15(n=13)$. b Epitope 2A, peptides 75 and $76(n=6)$. $\mathbf{c}$ Epitope 2B, peptides 76-77 $(n=5)$. d Epitope 3, peptides 8-9 $(n=$ 8). e Epitope 4, peptides 5 and $6(n=4)$. f Epitope 5, peptides 67 and $68(n=4)$. g Epitope 6, peptides 94 and $95(n=3)$. h Epitope 7, peptides 51 and $52(n=4)$. i Epitope 8, peptides 57 and $58(n=5)$ 
peptides 8 and 9 . We found that all eight responses were inhibited by an antibody to DP but not with other antibodies with a median of $97 \%$ inhibition ( $p=0.018$ in the Friedman test with Dunn's multiple comparisons) (Fig. 2d).

To identify the restriction to epitope 4, PBMC samples were stimulated with peptides 5 and 6 . Epitope 4 was presented by DR in 3/4 samples with a median of $110 \%$ inhibition (Fig. 2e). An inhibition $>100 \%$ can occur when the spots in the anti-DR wells have lower activation than the combination of anti-DR, DP, and DQ. One PBMC sample showed co-presentation of this epitope with $65 \%$ inhibition by DR and $33 \%$ by DQ.

For epitope 5, PBMC samples were stimulated with peptides 67 and 68. Epitope 5 was presented by DR in 3/4 samples with a median of $171 \%$ inhibition (Fig. 2f). One PBMC sample showed co-presentation of this epitope with $67 \%$ inhibition by DQ, $14 \%$ by DR, and $14 \%$ by DP.

For epitope 6, three PBMC samples were stimulated with peptides 94 and 95. Epitope 6 was presented by DR in $2 / 3$ samples with a median of $110 \%$ inhibition (Fig. $2 \mathrm{~g}$ ). One PBMC sample showed co-presentation of this epitope with $67 \%$ inhibition by DR and $25 \%$ by DQ.

For epitope 7, four PBMC samples were stimulated with peptides 51 and 52. Epitope 7 was presented by DR in 3/4 samples with a median of $96 \%$ inhibition (Fig. 2h) and $1 / 4$ samples was exclusively presented by DQ.

Finally, to identify the restriction to epitope 8 , five PBMC samples were stimulated with peptides 57 and 58 . Epitope 8 was presented by DR in $4 / 5$ samples with a median of $95 \%$ inhibition (Fig. 2i) and $1 / 5$ samples was exclusively presented by DQ. All five donors had moderate inhibition by DQ antibodies with a median of $43 \%$ inhibition.

The complete restriction for each epitope is summarized in Table II. Overall, we found that of 51 qualifying T-cell responses to PE38-derived epitopes, 33/51 (65\%) of the responses were exclusively restricted to DR, $12 / 51$ (24\%) to DP, and 2/51 (4\%) to DQ. Four out of $51(8 \%)$ of the responses were presented by more than a single presenting molecule, $2 / 51$ were co-presented by $\mathrm{DR}+\mathrm{DQ}$, and $2 / 51$ by all three $\mathrm{DR}+\mathrm{DP}+\mathrm{DQ}$.

\section{HLA Class II Molecule Density on the Surface of APCs}

To measure HLA class II expression on PBMCs, we used multicolor flow cytometry. As expected, we found that B cells (CD19+) and myeloid-derived dendritic cells (BDCA1+, BDCA2-) have a high expression of all three class II molecules (DR, DP, and DQ). Natural killer (CD56+) cells have very low expression and $\mathrm{T}$ cells $(\mathrm{CD} 3+\mathrm{CD} 4+$ or $\mathrm{CD} 3+\mathrm{CD} 8+$ ) have low but variable expression, which may reflect higher expression of HLA II molecules on activated Tcell populations (21). We did not investigate activation markers but focused our analysis on B cells and myeloidderived dendritic cells. To alleviate bias that could be introduced by laser compensation, the DR, DP, and DQ antibodies share the same FITC label and were added in separate tubes.

To examine whether the presentation of the PE38 epitopes on different MHCs is related to differential expression of DR, DP, or DQ, we separated the PBMC samples into two groups and analyzed for MHC expression levels using antibodies to DR or DP. Group 1 contained PBMCs that presented peptides on DP $(n=9)$. Group 2 contained PBMCs that presented peptides on DR $(n=6)$. We found that $\mathrm{T}$ cells of donors in group 1 do not have a significant difference in DP expression compared with donors in group 2, which did not present on DP, with average geometric means of $11.7 \pm 2.5$ and $12.0 \pm 2.0$, respectively (Fig. 3a). Similarly, no significant difference in expression was observed in myeloid-derived dendritic cells with median geometric means of $11.3 \pm 3.0$ and $12.0 \pm 3.0$ in groups 1 and 2, respectively (Fig. 3b). Furthermore, no significant differences were observed in the expression of DR in the two donor groups on B cells or myeloid-derived dendritic cells (Fig. 3c, d). We also found that no difference in DQ expression was observed (Fig. 3e, f). In summary, we did not find any significant differences between donor samples in group 1 and group 2 in their expression of HLA-DR, HLA-DP, or HLA-DQ on B cells and myeloidderived dendritic cells.

Table II. HLA Class II Restriction of PE38 Epitopes

\begin{tabular}{|c|c|c|c|c|c|c|c|c|}
\hline \multirow[t]{2}{*}{ Epitope no. } & \multirow[t]{2}{*}{ Peptides } & \multirow[t]{2}{*}{ Peptide sequence } & \multicolumn{5}{|c|}{ Restriction $^{\mathrm{a}}$} & \multirow[t]{2}{*}{ Total } \\
\hline & & & DR & DP & DQ & $\mathrm{DR}+\mathrm{DQ}^{\mathrm{b}}$ & $\mathrm{DR}+\mathrm{DP}+\mathrm{DQ}$ & \\
\hline 1 & $13-15$ & GYPVQRLVALYLAARLSWNQV & 12 & 0 & 0 & 0 & 1 & 13 \\
\hline $2 \mathrm{~A}+\mathrm{B}$ & $74-78$ & PDARGRIRNGALLRVYVPRSSLPGFYR & 6 & 4 & 0 & 0 & 0 & 10 \\
\hline 3 & $8-9$ & TRHRQPRGWEQLEQCGYP & 0 & 8 & 0 & 0 & 0 & 8 \\
\hline 4 & $5-6$ & ACHLPLETFTRHRQPRGW & 3 & 0 & 0 & 1 & 0 & 4 \\
\hline 5 & $67-68$ & WRGFYIAGDPALAYGYAQ & 3 & 0 & 0 & 0 & 1 & 4 \\
\hline $6 \mathrm{~A}+\mathrm{B}$ & $93-96$ & GPEEEGGRLETILGWPLAERTVVI & 2 & 0 & 0 & 1 & 0 & 3 \\
\hline 7 & $51-52$ & TVERLLQAHRQLEERGYV & 3 & 0 & 1 & 0 & 0 & 4 \\
\hline $8 \mathrm{~A}+\mathrm{B}$ & $56-59$ & GYVFVGYHGTFLEAAQSIVFGGVR & 4 & 0 & 1 & 0 & 0 & 5 \\
\hline Total & & & 33 & 12 & 2 & 2 & 2 & 51 \\
\hline
\end{tabular}

Three samples were excluded because the inhibition of all three class II molecules was $<70 \%$

${ }^{a}$ Responses were considered restricted to a specific class II molecule if it exhibits a normalized inhibition $>70 \%$

${ }^{b}$ Co-restriction was defined when two alleles or more were required for $>70 \%$ inhibition or when more than one molecule had $>70 \%$ inhibition 


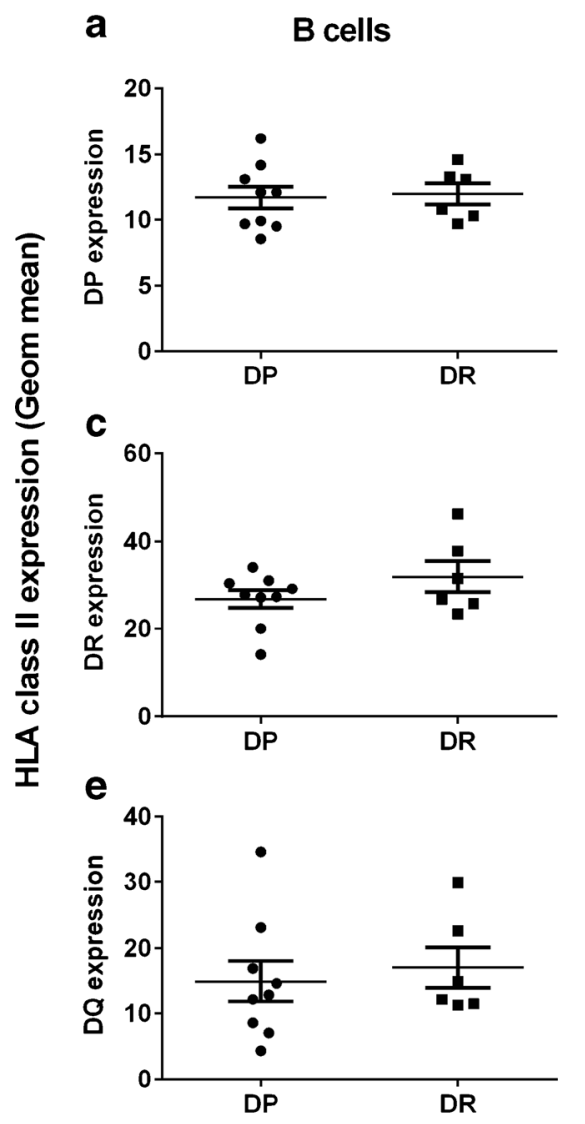

b Dendritic cells

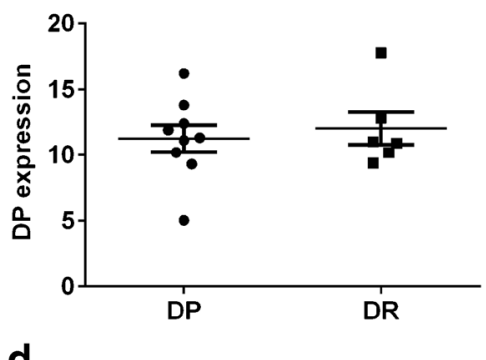

d
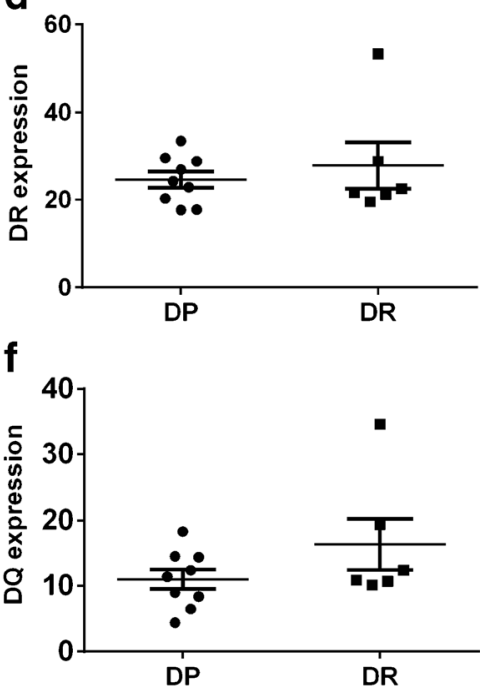

HLA II molecule involved in epitope presentation

Fig. 3. Density of DR, DP, and DQ in cells from DR- and DP-restricted donors on B cells and myeloid-derived dendritic cells. PBMCs from 15 donors were placed in two groups for DP- and DR-restricted responders and labeled with fluorescently labeled antibodies for cellular markers CD19, BDCA1, and BDCA2, as well as FITC-labeled antibodies targeting DP, DR, and DQ. Expression of DP on CD19+ lymphocytes (B cells) is shown in a, DR is shown in $\mathbf{c}$, and DQ is shown in e. Expression of DP on BDCA1+, BDCA2- myeloidderived dendritic cells is shown in $\mathbf{b}, \mathrm{DR}(\mathbf{d})$ and DP (f)

\section{HLA Types Within the Epitope Responder Groups}

To determine if the restricted responses occurred in donors with different HLA alleles, we analyzed the DNA of 36 samples for HLA DRB1, DR3/4/5, DQB1, and DPB1 (Table III).

To identify a common HLA allele in epitope 1 , we examined the different DR alleles in 13 samples that responded to this epitope and were mostly presented by DR. We found that all 13 samples had DRB5*01 or DRB5*02 in common and that $12 / 13$ samples also had DRB1*15 (*1501, *1502, or *1503) (Table III).

To identify common HLA molecule in epitope 2 (A and B), we examined the DR and DP alleles in 10 samples. We found that the DR-restricted samples were mixed with three donors expressing DRB1*1501, two donors expressing DRB1*0804, two expressing DRB1*1103/*1104, and a few expressing unique alleles like DRB1*0301 and DRB1*0401. DRB3/4/5 was heterogeneously expressed as well. While the donors restricted to DR do not have common DRB1 alleles, three of the four DPrestricted samples have DPB1*04 in common (Table III).

For epitope 3, we examined the different DP alleles in seven samples that responded to epitope 3 and were all presented by DP. We found that all samples have variable DPB1 alleles including DPB1*101, DPB1*401, and other alleles. A single common allele for all donors was not observed. This indicates a possible shared DP motif (Table III).

For epitope 4, we examined the different DR alleles in four samples that responded to this epitope and were mostly presented by DR. We found that 3/4 samples had DRB1*13 in common (1301 or 1302) (Table III).

To identify a common HLA allele in epitope 5, we examined the different DR alleles in three samples that responded to this epitope and were presented by DR. All three samples share a common DR3*02 allele (Table III).

For epitope 6, we examined the different DR alleles in three samples that responded to this epitope and were presented by $\mathrm{DR}$ or a combination of $(\mathrm{DR}+\mathrm{DQ})$. All three samples share a common DRB1*15 (1501 or 1503) (Table III).

For epitope 7, we examined the different DR alleles in four samples that responded to this epitope and were presented by either DR $(n=3)$ or DQ $(n=1)$. We found that the three DRrestricted samples did not share a common DR allele (Table III).

Finally, to identify a common HLA allele in epitope 8, we examined the different DR alleles in five samples that 
Table III. HLA Class II Alleles of Donors and Patients Used in the Study

\begin{tabular}{|c|c|c|c|c|c|c|c|c|c|c|}
\hline \multirow{3}{*}{$\begin{array}{l}\text { ID } \\
\text { Donor } 1\end{array}$} & \multicolumn{8}{|c|}{ HLA class II allele } & \multirow{3}{*}{$\begin{array}{l}\text { Epitope } \\
1,2 \mathrm{~B}\end{array}$} & \multirow{3}{*}{$\begin{array}{l}\text { Presenting molecule } \\
\text { DR, DR }\end{array}$} \\
\hline & \multicolumn{2}{|l|}{ DRB1* } & \multicolumn{2}{|c|}{ DRB3/4/5* } & \multicolumn{2}{|c|}{ DQB1* } & \multicolumn{2}{|c|}{ DPB1* } & & \\
\hline & 8:04 & 15:01 & $5 * 0101$ & & 03:01 & 06:02 & 04:01 & $17: 01$ & & \\
\hline Donor 2 & 04:07 & $15: 02$ & $4 * 0103$ & $5 * 0102$ & 03 & 06:01 & & & 1 & $\mathrm{DR}$ \\
\hline Donor 3 & 13:01 & $15: 03$ & $3 * 0101$ & $5 * 0101$ & 06 & 06 & & & 1,6 & $\mathrm{DR}(\mathrm{DR}+\mathrm{DQ})$ \\
\hline Donor 4 & 04:01 & 15:01 & $4 * 01$ & $5 * 01$ & 03:01 & 06:02 & 04:01 & 16:01 & 1,3 & DR, DP \\
\hline Donor 5 & 03:02 & $15: 03$ & $3 * 0101$ & $5 * 0101$ & 04:02 & 06:02 & & & 1 & DR \\
\hline Donor 6 & 07:01 & $15: 01$ & $4 * 01$ & $5 * 00$ & 03:03 & 06:02 & & & 1 & DR \\
\hline Donor 7 & 08:04 & $15: 03$ & $5 * 0101$ & & 06:02 & 06:02 & 10101 & 4001 & 1 & DR \\
\hline Donor 8 & $15: 01$ & $15: 02$ & $5 * 0102$ & $5 * 02$ & 05:03 & 06:02 & & & 1 & DR \\
\hline Donor 9 & 12:01 & 16:02 & $3 * 02$ & $5 * 0101$ & 05:01 & 05:02 & 09:02 & 85:01 & 1 & DR \\
\hline Donor 10 & 14:01 & $15: 01$ & $3 * 0202$ & $5 * 0101$ & $05: 03$ & 06:02 & 40101 & 2301 & 1 & DR \\
\hline Donor $11^{\mathrm{a}}$ & 08:03 & $15: 02$ & $5 * 01$ & & 05:01 & 06:01 & $36: 01$ & 13:01 & $1,3,4$ & DR, DP, DR \\
\hline Donor 12 & 08:06 & 15:01 & $5 * 01$ & & 05:01 & 06:02 & 03:01 & 04:01 & 1,6 & $\mathrm{DR}, \mathrm{DR}$ \\
\hline Donor 13 & $15: 01$ & $15: 03$ & & & 06:02 & 06:02 & 04:01 & 40:01 & $2 \mathrm{~A}$ & DP \\
\hline Donor 14 & 03:01 & 11:04 & $3 * 0101$ & $3 * 0202$ & 02:01 & 03:01 & 04:02 & 04:02 & $2 \mathrm{~A}, 2 \mathrm{~B}$ & DP \\
\hline Donor 15 & 09:01 & 13:01 & $3 * 02$ & $4 * 01$ & 02:02 & 03:03 & 01:01 & 105: 01 & $2 \mathrm{~A}$ & $\mathrm{DP}$ \\
\hline Donor 16 & 04:01 & 04:04 & $4 * 0103$ & & 03:02 & 03:02 & 02:01 & 18:01 & $2 \mathrm{~B}$ & DR \\
\hline Donor 17 & 08:04 & 13 & $3 * 0101$ & & 03:01 & 04:02 & & & $2 \mathrm{~B}$ & DR \\
\hline Donor 18 & 03:01 & 04:01 & $3 * 01$ & $04 * 0103$ & 02:01 & 03:01 & & & 3 & DP \\
\hline Donor 19 & 03:01 & 03:02 & $3 * 0101$ & $3 * 0202$ & 02:01 & 04:02 & 01:01 & 105:01 & 3,5 & DP, DR \\
\hline Donor 20 & 01:01 & 03:01 & $3 * 0101$ & & 02:01 & 05:01 & 01:01 & 03:01 & 3 & $\mathrm{DP}$ \\
\hline Donor 21 & 04:01 & $13: 02$ & $3 * 0301$ & $4 * 01$ & 03:01 & 06:09 & 04:01 & 05:01 & 3 & DP \\
\hline Donor 22 & 10:01 & $13: 02$ & $3 * 0202$ & $3 * 0303$ & 03:01 & 05:01 & 01:01 & 02:01 & 3 & DP \\
\hline Donor 23 & 07:01 & 07:01 & $4 * 0103$ & & 02:02 & & 01:01 & 02:01 & 3 & DP \\
\hline Donor 24 & 04:01 & 13 & $3 * 0202$ & $4 * 0103$ & 03:02 & 06:03 & 03:01 & 04:02 & 4 & DR \\
\hline Donor $25^{\mathrm{b}}$ & 12:01 & 13:01 & & & 05:01 & 06: 03 & & & 4 & DR \\
\hline Donor 26 & 08:04 & $13: 02$ & $3 * 0301$ & & 3 & 5 & 01:01 & 02:01 & 4 & $(\mathrm{DR}+\mathrm{DQ})$ \\
\hline Donor 27 & 03:01 & 07:01 & $3 * 02$ & $4 * 01$ & 02:01 & 02:02 & 01:01 & $85: 01$ & 5,8 & DR, DR \\
\hline Donor 28 & 11:01 & $13: 02$ & $03 * 0202$ & $03 * 0301$ & 3 & 05:01 & 01:01 & 02:01 & 5 & $(\mathrm{DR}+\mathrm{DP}+\mathrm{DQ})$ \\
\hline Donor 29 & 15:01 & $15: 02$ & $05 * 01$ & & 06:01 & 06:02 & 04:01 & 104:01 & 7 & DQ \\
\hline Donor 30 & 04:01 & $13: 03$ & & & 03:01 & 03:02 & 29:01 & 105:01 & 7 & DR \\
\hline Donor 31 & 07:01 & 08:04 & $04 * 01$ & & 02:02 & 03:19 & 01:01 & 11:01 & 7,8 & DR, DR \\
\hline Patient 1 & 07:01 & $15: 01$ & & & 02:02 & 06:02 & 02:01 & 04:01 & $1,2 \mathrm{~A}, 6,8$ & DR, DR, DR, DR \\
\hline Patient 2 & 15:01 & 15:01 & & & 06:02 & 06:02 & 04:01 & 04:02 & $2 \mathrm{~B}$ & DR \\
\hline Patient 3 & 04:01 & $12: 01$ & & & 03:01 & 03:01 & 04:01 & 05:01 & $2 \mathrm{~A}$ & DP \\
\hline Patient $4^{\mathrm{c}}$ & 01:03 & 03:01 & & & 02:01 & 03:01 & $25: 01$ & 20:01 & 8 & DR \\
\hline Patient $5^{\mathrm{d}}$ & $11: 03$ & $13: 03$ & & & 03:01 & 03:01 & $2: 01$ & 23:01 & $2 \mathrm{~A}, 5,7,8$ & $\mathrm{DR}, \mathrm{DR}, \mathrm{DR}, \mathrm{DQ}$ \\
\hline
\end{tabular}

${ }^{a}$ Could not rule out DPB1*135:01 and 107: 01, 173: 01

${ }^{b}$ Could not rule out DRB1*12:06, 12:10, 12:17, DRB1*13:117, DQB1*105:07, 05: 11, 05:12 and DQB1*06:28, 06:31, 06:41, 06:44

${ }^{c}$ Could not rule out DPB1*75:01, 79:01, 132:01, 164:01, 271:01, 36:801 and DPB1*50:01, 57:01, 59:01, 68:01, 80:01, 108:01

${ }^{d}$ Could not rule out DPB1*71:01 and DPB1*105:01

were presented by either DR $(n=4)$ or DQ $(n=1)$. We found that the four DR-restricted samples did not share a common DR allele (Table III).

Interestingly, we observed that the two donors that had complete inhibition by DQ antibodies (in epitopes 7 and 8) were both homozygous (DQB1*06 for epitope 7 and DQB1*0301 in epitope 8). Overall, we found that several alleles and loci are involved in the presentation of the eight epitopes in PE38.

\section{Can Multiple HLA Class II Molecules Be Used to Present Different Epitopes?}

To examine if donors that responded to more than one epitope in PE38 use a single type of presenting molecule or different presentation molecules, we examined responses from nine PBMC samples that had a robust response to more than one epitope. Table IV shows the epitopes and restriction results for each of the samples. Five of the individuals had all their responses presented exclusively by DR, three individuals had a mixed restriction pattern in which one epitope was presented by DR and another by DP, and two individuals had mixed presentation on DR and DQ. These data show that an individual can use more than one HLA molecule to present different epitopes.

\section{Prediction of PE38 Epitopes Using DR, DP, and DQ Binding Algorithm}

Because we found that DP and DQ molecules are involved in the presentation of PE38 peptides, we used the IEDB prediction algorithm to analyze the six most common 
Table IV. T-Cell Restriction in Individuals with more than One Epitope

\begin{tabular}{lll}
\hline ID & Epitopes & Presenting molecule \\
\hline D1 & $1,2 \mathrm{~B}$ & DR, DR \\
D2 & 1,6 & DR (DR+DQ) \\
D3 & 1,3 & DR, DP \\
D4 & $1,3,4$ & DR, DP, DR \\
D5 & 1,6 & DR, DR \\
D6 & $2 \mathrm{~A}, 2 \mathrm{~B}$ & DP, DP \\
D7 & 3,5 & DP, DR \\
D8 & 5,8 & DR, DR \\
D9 & 7,8 & DR, DR \\
P1 & $1,2 \mathrm{~A}, 6,8$ & DR, DR, DR, DR \\
P2 & $2 \mathrm{~A}, 5,7,8$ & DR, DR, DR, DQ \\
\hline
\end{tabular}

DP and DQ alleles in the worldwide population. These alleles were selected because they cover 95 and $82 \%$ of DP and DQ phenotype frequency in major ethnicities worldwide (34). Table $\mathrm{V}$ shows the number of alleles predicted to bind to experimentally determined PE38 peptides using a cutoff of $20 \%$ percentile rank. The $20 \%$ cutoff was chosen because it is frequently used for T-cell epitope prediction (35-37) and because we previously found in DR binding prediction analysis that this threshold accepts many peptides as positive and has a relatively low rate of false negative predictions (false negative rate was $30 \%$ and $55 / 111$ peptides were considered positive in this threshold in DR predictions) (26). We define epitopes as peptides that are predicted to bind to a third of the reference alleles or more. Thus, $\geq 9 / 27$ HLA class II alleles would be considered as an epitope by prediction. For analysis of DP alleles, $\geq 2 / 6$ DP alleles were considered as an epitope, and similarly 2/6 alleles for DQ binding. These predictions are in italics in Table V.

We found that none of the HLA-DP reference alleles were predicted to bind the peptides in epitope region 3 (peptides 8-9). This was surprising because this epitope is restricted to DP and is a strong epitope. We considered the possibility that DP alleles may require a different cutoff. We found that peptide 9 would have been predicted as a binder with a cutoff of $47 \%$ and peptide 8 with a cutoff of $67 \%$. These thresholds would consider 68 and 82 of the 111 peptides as positive binders.

Overall, inclusion of DP and DQ in the HLA class II analysis did not improve the accuracy of the overall prediction. Seven of the eight epitopes had at least one peptide predicted correctly in the analysis of 15 DR reference alleles; however, only six out of the eight epitopes were predicted in the analysis using 27 HLA class II alleles.

\section{DISCUSSION}

The role of non-DR class II presentation in immunogenicity of vaccines and protein therapeutics has been undervalued in the past few years $(8-16,38)$. To understand the relationship between T-cell epitopes, their presentation by HLA class II molecules, and their potential to be predicted based on commonly used in silico binding algorithm, we experimentally determined which HLA class II molecules were responsible for their presentation. We found that DR restricted $65 \%$ of the responses and that DP and DQ restricted the other $35 \%$ of the responses. In addition, we found one important epitope that was only DP restricted. This epitope was undetected using DR, DQ, or DP high affinity binding predictions.

Our results indicate an important role for DP in the presentation of PE38 epitopes; $24 \%$ were DP restricted and $4 \%$ were DQ restricted. Non-DR-restricted T-cell epitopes in foreign and nonforeign proteins have been observed in several other proteins including influenza A Puerto Rico/8/ 34 matrix protein, Epstein-Barr virus (EBV)-encoded nuclear antigen 1, adenovirus hexon, dengue virus, streptococcal M12 protein, tetanus toxin, dimorphic fungus, and the NY-ESO-1 tumor antigen (39-45). Also the susceptibility to several diseases, including infectious diseases, is associated with DPand DQ-restricted epitopes (46-49).

The identification of non-DR epitopes has a high translational value in the development of vaccines and for the therapy of allergy because HLA-DQ and HLA-DP subtypes are more conserved across populations than HLADR subtypes. For example, HLA-DPB*0401 and HLADPB*0402 alleles are present together in $\sim 50 \%$ of the Caucasian population (50). Therefore, the role of DP epitopes in the immune response should always be taken into account. The distribution of restriction elements in our study $(35 \%$ non-DR) is in agreement with Mellins et al. that found that approximately $40 \%$ of the T-cell proliferation responses to purified protein derivative (PPD) and tetanus toxoid were restricted by non-DR class II molecules (51).

We found that two of the donors that responded to epitope 3, which is entirely DP restricted, share the same DPB1 allele DPB1*0201; however, two additional donors that did not respond to this epitope also share the same DPB1 allele (Table III). This finding indicates that the alleles for DP beta chain are not sufficient to determine whether a specific peptide will activate T cells. Other factors that may affect the restriction include the DPA chain and the availability of $\mathrm{T}$ cells. Similarly, not all donors with a specific DR allele respond to the same epitopes; a donor with a DR-restricted T-cell response to epitope $2 \mathrm{~B}$ is homozygote to DRB1*1501 allele (Table III). Based on the haplotype of the DR molecules involved in the response in conjunction with the result that the epitope is presented by DR, one would expect that all donors that have DRB1*1501 will have a positive response to epitope $2 \mathrm{~B}$. However, this is not the case. Several donors with a DRB1*1501 allele did not respond to epitope 2, including primed patients. This finding points out that HLA binding to DRB1 molecules is required but not sufficient to drive T-cell activation, for example DRB3/4/5 could be presenting the epitope as well.

We previously reported the identification and restriction of epitope 1 (27). Here, the restriction analysis for this epitope was repeated and included in the analysis of all eight epitopes in PE38. Minor changes were made in the methodology including stimulation with a 21 mer peptide (spanning peptides 13, 14, and 15 ) and not peptide 15 alone which is 15 mer. In addition, different PBMC samples were used for the most part because many of the PBMC samples that were used in 2012 were no longer available. In the restriction analysis in 2012, we found that 9/9 samples were restricted to DR. Similarly, the restriction 
Table V. HLA Binding Prediction for DR, DP, and DQ PE38 Peptides

\begin{tabular}{|c|c|c|c|c|c|c|}
\hline \multirow[b]{2}{*}{ Epitope } & \multirow[b]{2}{*}{ Peptide ID } & \multirow{2}{*}{$\begin{array}{l}\text { Experimental } \\
\text { responses }\end{array}$} & \multicolumn{3}{|c|}{ Number of predicted alleles } & \multirow[b]{2}{*}{$\begin{array}{l}\text { HLA class } \\
\text { II }\end{array}$} \\
\hline & & & DR & DP & DQ & \\
\hline \multirow{3}{*}{1} & 13 & 6 & 14 & 6 & 3 & 23 \\
\hline & 14 & 19 & 14 & 6 & 5 & 25 \\
\hline & 15 & 22 & 12 & 6 & 3 & 21 \\
\hline \multirow{5}{*}{2} & 74 & 3 & 10 & 1 & 0 & 11 \\
\hline & 75 & 4 & 10 & 1 & 2 & 13 \\
\hline & 76 & 9 & 13 & 1 & 1 & 15 \\
\hline & 77 & 12 & 13 & 1 & 0 & 14 \\
\hline & 78 & 11 & 10 & 0 & 0 & 10 \\
\hline \multirow{2}{*}{3} & 8 & 10 & 0 & 0 & 0 & 0 \\
\hline & 9 & 8 & 0 & 0 & 0 & 0 \\
\hline \multirow{2}{*}{4} & 5 & 7 & 4 & 2 & 0 & 6 \\
\hline & 6 & 8 & 6 & 1 & 0 & 7 \\
\hline \multirow{2}{*}{5} & 67 & 7 & 13 & 3 & 4 & 20 \\
\hline & 68 & 8 & 9 & 1 & 4 & 14 \\
\hline \multirow{4}{*}{6} & 93 & 4 & 0 & 1 & 0 & 1 \\
\hline & 94 & 5 & 6 & 1 & 0 & 7 \\
\hline & 95 & 5 & 10 & 4 & 2 & 16 \\
\hline & 96 & 2 & 5 & 2 & 2 & 9 \\
\hline \multirow{2}{*}{7} & 51 & 4 & 6 & 3 & 1 & 10 \\
\hline & 52 & 3 & 3 & 1 & 0 & 4 \\
\hline \multirow{4}{*}{8} & 56 & 3 & 10 & 5 & 6 & 21 \\
\hline & 57 & 4 & 9 & 5 & 6 & 20 \\
\hline & 58 & 3 & 13 & 4 & 6 & 23 \\
\hline & 59 & 1 & 8 & 2 & 3 & 13 \\
\hline
\end{tabular}

Number of positive alleles for DR, DP, DQ, or all three (HLA class II) was predicted at a threshold of $20 \%$. Values in italics represent $\geq 33 \%$ of alleles in each group (5/15 alleles for DR, 2/6 alleles for DP and DQ, and 9/27 alleles all class II alleles)

results shown in Fig. 2a show that 12/13 samples were completely restricted to $\mathrm{DR}$ and $1 / 13$ was restricted by a combination of $\mathrm{DR}$, DP, and DQ when DR had the strongest inhibition of the three. The difference in the restriction pattern that was observed in one sample can be explained by the longer peptide length used in the experiment. We extended the HLA typing of 12 of these samples to the DR3/4/5 in this study. We found that all 12 samples that responded to epitope 1 share a locus of DRB5*101 or DRB5*102. Furthermore, 11/12 samples also share DRB1*15; this is not surprising because DRB5 and DRB1*15 are genetically linked (52). We note that other factors in addition to the HLA binding can affect T-cell activation; these factors include a combination with variable alpha chains (for DP), T-cell availability, and regulatory functions (53).

To understand the mechanism of preferable DP presentation, we examined whether higher expression of DP molecules, which has been shown to be linked to a genetic polymorphism in the HLA-DPB1 gene regulatory region
(48), could affect the restriction of the epitopes in our ex vivo settings. We did not find a significant difference in DP, DR, or DQ membrane expression analyzing DP- and DR-restricted PBMC samples. We do not have sufficient DQ-restricted responses to make a similar determination regarding DQ.

The fact that epitope 3 was not predicted using the previous DR prediction analysis (26) is due to the fact that this epitope was $100 \%$ restricted to DP and because DR molecules have different binding cores and binding affinities from DP (54). However, it is surprising that predictions using reference DP alleles did not recognize this epitope as a binder. The threshold we used (of $20 \%$ percentile rank) is not a stringent one for epitope prediction and should support a low rate of false negative predictions.

Sidney et al. defined binding motifs for common DP alleles and also a super motif that is common for multiple DP binding cores (54). This motif includes a canonical P1-P6 main anchor spacing with aromatic/hydrophobic residues at 
positions $\mathrm{P} 1$ and $\mathrm{P} 6$. This requirement for an aromatic/ hydrophobic residue at position 6 is different from binding motifs for DRB molecules that are usually associated with a small or charged residue in this position (54). The common amino acid sequence between the overlapping, DP-restricted, peptides 8 and 9 is ${ }^{276}$ RQPRGWEQLEQC ${ }^{287}$, which fits the canonical anchor of DPB1*0101 with W281 at position P1 and Q286 at position P6 (54). Nevertheless, prediction of peptides 8 and 9 in DPB1*0101 had a binding score of 50 and $49 \%$, respectively. The fit of this peptide to the canonical anchor motif makes the inability of the DP algorithm to predict the binding of this epitope even more puzzling.

Because we found that $35 \%$ of the responses were nonDR, we expected that inclusion of DP and DQ alleles in the prediction query will improve the accuracy of the predicted epitopes, but that was not the case. We found that while seven out of the eight epitopes had at least one peptide predicted to bind in high affinity in the analysis of 15 DR alleles, only six out of the eight were predicted to bind in a high affinity in the analysis of 27 DR, DP, and DQ alleles. This discrepancy is due to the fact that the peptide needed to be predicted as strong binders in $33 \%$ of the alleles ( $9 / 27$ alleles in DR, DP, and DQ analysis but only $5 / 15$ in the DR analysis). It is possible that DP and DQ predictions need different and separate thresholds from DR for better accuracy.

Our observation that binding predictions of DP alleles missed an important epitope is supported by the findings of Paul et al. (55). They analyzed the accuracy of HLA binding predictions of 1151 peptides from 30 different proteins and found that inclusion of DP alleles in the in silico analysis resulted in a lower accuracy than when excluding them, although some of those experimental epitopes were indeed DP restricted. They suggested that the poor accuracy for DP predictions is a result of insufficient binding data available that drives the learning of the algorithm.

The second strongest epitope in PE38 (epitope 2) in amino acids PDARGRIRNGALLRVYVPRSSLPGFYR (peptides 74-78) is a complex epitope because T-cell stimulation was produced by more than three overlapping peptides. This indicates more than a single 9 mer core. Interestingly, most of the peptides at the N-terminus of the epitope ( $2 \mathrm{~B}$ in peptides 74,75 , or 76 ) were DR restricted and most of the peptides at the C-terminus (2A, peptides 76,77 , or 78) were DP restricted. This is an example of both intralocus and interlocus cross reactivity, a feature that was documented in several antigenic epitopes including viruses (hepatitis $\mathrm{B}$ virus and hepatitis $\mathrm{C}$ virus), toxins (tetanus toxin), and allergen (Hay fever and German cockroach) (31,35,56-58). Additional examples of interloci cross reactivity were observed in this study in four donors that had copresentation of the same epitope either by a combination of two loci $(\mathrm{DR}+\mathrm{DQ})$ or all three (DR, DP, DQ) (Table II). Intra- or interlocus cross-reactive epitopes may not always be due to the presence of a single promiscuous core region but rather may be caused by multiple overlapping core regions, each binding different HLA molecules (54). A similar phenomenon of epitope/motif clustering was reported by Berzofsky et al. who found that a few overlapping yet distanced peptides from the HIV envelope protein were recognized by $52-73 \%$ of 42 HLA diverse infected human donors and also by four MHC class II mice haplotypes (59).
From an immunogenicity-protein engineering perspective, the intra/interlocus cross reactivity by DR and DP of epitopes $2 \mathrm{~A}$ and $2 \mathrm{~B}$ poses a problem because it is difficult to identify point mutations that will prevent class II presentation of the epitope without affecting protein function. On the other hand, this same trait makes this epitope a valuable candidate to be included in a much needed vaccine design for Pseudomonas aeruginosa (60), because such epitopes will be useful to activate the immune system of a very diverse HLA class II population.

\section{CONCLUSION}

In conjunction with recent discoveries of the important role that HLA-DP plays in multiple immune conditions, we provide an analysis of the relationship between T-cell epitopes in PE38, class II presentations of those epitopes, and a failure to predict an important T-cell epitope in an analysis that is based on class II HLA binding. We conclude that DP plays a critical role in the immunogenicity of PE38 and that widely used predictions that are based on HLA prediction algorithms are not sufficient to accurately predict some T-cell epitopes. We propose that inclusion of HLA-DP allele in prediction analysis will be useful and that DP alleles should be taken into consideration in population coverage cohorts. Furthermore, it is necessary to produce more DP binding datasets to try and increase the accuracy of DP binding algorithms. At the current time, an experimental approach such as that described by Sette and colleagues (31) is necessary to correctly identify T-cell epitopes.

\section{ACKNOWLEDGMENTS}

This research was supported by the Intramural Research Program of the NIH, National Cancer Institute, Center for Cancer Research (Project \# ZO1 BC008753-26). We thank Dr. Zuben Sauna for his helpful comments in reviewing the manuscript.

\section{REFERENCES}

1. Roche PA, Furuta K. The ins and outs of MHC class II-mediated antigen processing and presentation. Nat Rev Immunol. 2015;15(4):203-16.

2. Cresswell P. Assembly, transport, and function of MHC class II molecules. Annu Rev Immunol. 1994;12:259-93.

3. Wang P, Sidney J, Kim Y, Sette A, Lund O, Nielsen M, et al. Peptide binding predictions for HLA DR, DP and DQ molecules. BMC Bioinf. 2010;11:568.

4. Sbai H, Mehta A, DeGroot AS. Use of T cell epitopes for vaccine development. Curr Drug Targets Infect Disord. 2001;1(3):303-13.

5. Stevanovic S. Identification of tumour-associated T-cell epitopes for vaccine development. Nat Rev Cancer. 2002;2(7):514-20.

6. Sette A, Rappuoli R. Reverse vaccinology: developing vaccines in the era of genomics. Immunity. 2010;33(4):530-41.

7. Anderson RP, Jabri B. Vaccine against autoimmune disease: antigen-specific immunotherapy. Curr Opin Immunol. 2013;25(3):410-7.

8. Cantor JR, Yoo TH, Dixit A, Iverson BL, Forsthuber TG, Georgiou G. Therapeutic enzyme deimmunization by combinatorial T-cell epitope removal using neutral drift. Proc Natl Acad Sci U S A. 2011;108(4):1272-7. 
9. Salvat RS, Choi Y, Bishop A, Bailey-Kellogg C, Griswold KE Protein deimmunization via structure-based design enables efficient epitope deletion at high mutational loads. Biotechnol Bioeng. 2015;112:1306-18.

10. King C, Garza EN, Mazor R, Linehan JL, Pastan I, Pepper M, et al. Removing T-cell epitopes with computational protein design. Proc Natl Acad Sci U S A. 2014;111(23):8577-82.

11. Tangri S, Mothe BR, Eisenbraun J, Sidney J, Southwood S, Briggs $\mathrm{K}$, et al. Rationally engineered therapeutic proteins with reduced immunogenicity. J Immunol. 2005;174(6):3187-96.

12. Koren E, De Groot AS, Jawa V, Beck KD, Boone T, Rivera D, et al. Clinical validation of the "in silico" prediction of immunogenicity of a human recombinant therapeutic protein. Clin Immunol. 2007;124(1):26-32.

13. Abdel-Hady KM, Gutierrez AH, Terry F, Desrosiers J, De Groot AS, Azzazy HM. Identification and retrospective validation of Tcell epitopes in the hepatitis $C$ virus genotype 4 proteome: an accelerated approach toward epitope-driven vaccine development. Hum Vaccin Immunother. 2014;10(8):2366-77.

14. Iwai LK, Yoshida M, Sidney J, Shikanai-Yasuda MA, Goldberg AC, Juliano MA, et al. In silico prediction of peptides binding to multiple HLA-DR molecules accurately identifies immunodominant epitopes from gp43 of Paracoccidioides brasiliensis frequently recognized in primary peripheral blood mononuclear cell responses from sensitized individuals. Mol Med. 2003;9(9-12):209-19.

15. Li X, Yang $\mathrm{HW}$, Chen $\mathrm{H}, \mathrm{Wu} \mathrm{J}$, Liu $\mathrm{Y}$, Wei JF. In silico prediction of $\mathrm{T}$ and $\mathrm{B}$ cell epitopes of Der f 25 in Dermatophagoides farinae. Int J Gen. 2014;2014:483905.

16. Salvat RS, Parker AS, Guilliams A, Choi Y, Bailey-Kellogg C, Griswold KE. Computationally driven deletion of broadly distributed $\mathrm{T}$ cell epitopes in a biotherapeutic candidate. Cell Mol Life Sci. 2014;71:4869-80.

17. Ottenhoff TH, Elferink DG, Hermans J, de Vries RR. HLA class II restriction repertoire of antigen-specific $\mathrm{T}$ cells. I. The main restriction determinants for antigen presentation are associated with HLA-D/DR and not with DP and DQ. Hum Immunol. 1985;13(2):105-16.

18. Spurzem JR, Saltini C, Kirby M, Konishi K, Crystal RG. Expression of HLA class II genes in alveolar macrophages of patients with sarcoidosis. Am Rev Respir Dis. 1989;140(1):89-94.

19. Meyer CG, May J, Schnittger L. HLA-DP-part of the concert. Immunol Today. 1997;18(2):58-61.

20. Maurer DH, Hanke JH, Mickelson E, Rich RR, Pollack MS. Differential presentation of HLA-DR, DQ, and DP restriction elements by interferon-gamma-treated dermal fibroblasts. J Immunol. 1987;139(3):715-23.

21. Gansbacher B, Zier KS. Regulation of HLA-DR, DP, and DQ expression in activated T cells. Cell Immunol. 1988;117(1):22-34.

22. Kreitman RJ. Immunoconjugates and new molecular targets in hairy cell leukemia. Hematol Am Soc Hematol Educ Prog. 2012;2012:660-6.

23. Kreitman RJ, Tallman MS, Robak T, Coutre S, Wilson WH, Stetler-Stevenson M, et al. Phase I trial of anti-CD22 recombinant immunotoxin moxetumomab pasudotox (CAT-8015 or HA22) in patients with hairy cell leukemia. J Clin Oncol. 2012;30(15):1822-8.

24. Hassan R, Bullock S, Premkumar A, Kreitman RJ, Kindler H, Willingham MC, et al. Phase I study of SS1P, a recombinant antimesothelin immunotoxin given as a bolus I.V. infusion to patients with mesothelin-expressing mesothelioma, ovarian, and pancreatic cancers. Clin Cancer Res. 2007;13(17):5144-9.

25. Mazor R, Eberle JA, Hu X, Vassall AN, Onda M, Beers R, et al. Recombinant immunotoxin for cancer treatment with low immunogenicity by identification and silencing of human T-cell epitopes. Proc Natl Acad Sci U S A. 2014;111(23):8571-6.

26. Mazor R, Tai CH, Lee B, Pastan I. Poor correlation between Tcell activation assays and HLA-DR binding prediction algorithms in an immunogenic fragment of Pseudomonas exotoxin A. J Immunol Methods. 2015;425:10-20.

27. Mazor R, Vassall AN, Eberle JA, Beers R, Weldon JE, Venzon $\mathrm{DJ}$, et al. Identification and elimination of an immunodominant T-cell epitope in recombinant immunotoxins based on Pseudomonas exotoxin A. Proc Natl Acad Sci U S A. 2012;109(51):E3597-603.
28. Kwok WW, Liu AW, Novak EJ, Gebe JA, Ettinger RA, Nepom GT, et al. HLA-DQ tetramers identify epitope-specific T cells in peripheral blood of herpes simplex virus type 2 -infected individuals: direct detection of immunodominant antigen-responsive cells. J Immunol. 2000;164(8):4244-9.

29. Vita R, Overton JA, Greenbaum JA, Ponomarenko J, Clark JD, Cantrell JR, et al. The immune epitope database (IEDB) 3.0. Nucleic Acids Res. 2015;43(Database issue):D405-12.

30. Zhu F, Xu H, Tsao A, Margolis DA, Keever-Taylor CA. Generation of cytotoxic T-cell lines using overlapping pentadecapeptides derived from conserved regions of the adenovirus hexon protein. J Gen Virol. 2010;91(Pt 6):1577-89.

31. Oseroff C, Sidney J, Kotturi MF, Kolla R, Alam R, Broide DH, et al. Molecular determinants of T cell epitope recognition to the common Timothy grass allergen. J Immunol. 2010;185(2):943-55.

32. Kuan CT, Pastan I. Improved antitumor activity of a recombinant anti-Lewis(y) immunotoxin not requiring proteolytic activation. Proc Natl Acad Sci U S A. 1996;93(3):974-8.

33. Wang P, Sidney J, Dow C, Mothe B, Sette A, Peters B. A systematic assessment of MHC class II peptide binding predictions and evaluation of a consensus approach. PLoS Comput Biol. 2008;4(4):e1000048.

34. Greenbaum J, Sidney J, Chung J, Brander C, Peters B, Sette A. Functional classification of class II human leukocyte antigen (HLA) molecules reveals seven different supertypes and a surprising degree of repertoire sharing across supertypes. Immunogenetics. 2011;63(6):325-35.

35. Oseroff C, Sidney J, Tripple V, Grey H, Wood R, Broide DH, et al. Analysis of $\mathrm{T}$ cell responses to the major allergens from German cockroach: epitope specificity and relationship to $\operatorname{IgE}$ production. J Immunol. 2012;189(2):679-88.

36. Oseroff C, Sidney J, Vita R, Tripple V, McKinney DM, Southwood $\mathrm{S}$, et al. $\mathrm{T}$ cell responses to known allergen proteins are differently polarized and account for a variable fraction of total response to allergen extracts. J Immunol. 2012;189(4):1800-11.

37. Schulten V, Greenbaum JA, Hauser M, McKinney DM, Sidney J, Kolla R, et al. Previously undescribed grass pollen antigens are the major inducers of $\mathrm{T}$ helper 2 cytokine-producing $\mathrm{T}$ cells in allergic individuals. Proc Natl Acad Sci U S A. 2013;110(9):345964.

38. Jawa V, Cousens LP, Awwad M, Wakshull E, Kropshofer H, De Groot AS. T-cell dependent immunogenicity of protein therapeutics: preclinical assessment and mitigation. Clin Immunol. 2013;149(3):534-55.

39. Zeng G, Wang $X$, Robbins PF, Rosenberg SA, Wang RF. $\mathrm{CD} 4(+) \mathrm{T}$ cell recognition of MHC class II-restricted epitopes from NY-ESO-1 presented by a prevalent HLA DP4 allele: association with NY-ESO-1 antibody production. Proc Natl Acad Sci U S A. 2001;98(7):3964-9.

40. Yang J, Huston L, Berger D, Danke NA, Liu AW, Disis ML, et al. Expression of HLA-DP0401 molecules for identification of DP0401 restricted antigen specific T cells. J Clin Immunol. 2005;25(5):428-36.

41. Voo KS, Fu T, Heslop HE, Brenner MK, Rooney CM, Wang RF. Identification of HLA-DP3-restricted peptides from EBNA1 recognized by CD4(+) T cells. Cancer Res. 2002;62(24):7195-9.

42. Tang J, Olive M, Champagne K, Flomenberg N, Eisenlohr L, Hsu S, et al. Adenovirus hexon T-cell epitope is recognized by most adults and is restricted by HLA DP4, the most common class II allele. Gene Ther. 2004;11(18):1408-15.

43. Kurane I, Dai LC, Livingston PG, Reed E, Ennis FA. Definition of an HLA-DPw2-restricted epitope on NS3, recognized by a dengue virus serotype-cross-reactive human CD4+ CD8- cytotoxic T-cell clone. J Virol. 1993;67(10):6285-8.

44. Dong RP, Kamikawaji N, Toida N, Fujita Y, Kimura A, Sasazuki T. Characterization of T cell epitopes restricted by HLA-DP9 in streptococcal M12 protein. J Immunol. 1995;154(9):4536-45.

45. Chang WL, Audet RG, Aizenstein BD, Hogan LH, DeMars RI, Klein BS. T-cell epitopes and human leukocyte antigen restriction elements of an immunodominant antigen of Blastomyces dermatitidis. Infect Immun. 2000;68(2):502-10.

46. Kamatani Y, Wattanapokayakit S, Ochi H, Kawaguchi T, Takahashi A, Hosono N, et al. A genome-wide association study identifies variants in the HLA-DP locus associated with chronic hepatitis B in Asians. Nat Genet. 2009;41(5):591-5. 
47. Nishida N, Sawai H, Kashiwase K, Minami M, Sugiyama M, Seto WK, et al. New susceptibility and resistance HLA-DP alleles to HBV-related diseases identified by a trans-ethnic association study in Asia. PLoS One. 2014;9(2):e86449.

48. Petersdorf EW, Malkki M, O'HUigin C, Carrington $\mathrm{M}$, Gooley T, Haagenson MD, et al. High HLA-DP expression and graft-versus-host disease. N Engl J Med. 2015;373(7):599609.

49. Ito H, Yamasaki K, Kawano Y, Horiuchi I, Yun C, Nishimura Y, et al. HLA-DP-associated susceptibility to the optico-spinal form of multiple sclerosis in the Japanese. Tissue Antigens. 1998;52(2):179-82.

50. Castelli FA, Buhot C, Sanson A, Zarour H, Pouvelle-Moratille S, Nonn C, et al. HLA-DP4, the most frequent HLA II molecule, defines a new supertype of peptide-binding specificity. J Immunol. 2002;169(12):6928-34.

51. Mellins E, Woelfel M, Pious D. Importance of HLA-DQ and DP restriction elements in T-cell responses to soluble antigens: mutational analysis. Hum Immunol. 1987;18(3):211-23.

52. Marsh SGE, Parham P, Barber LD. The HLA factsbook. London: Academic; 2000.

53. Parker DC. T cell-dependent B cell activation. Annu Rev Immunol. 1993;11:331-60.

54. Sidney J, Steen A, Moore C, Ngo S, Chung J, Peters B, et al. Five HLA-DP molecules frequently expressed in the worldwide human population share a common HLA supertypic binding specificity. J Immunol. 2010;184(5):2492-503.

55. Paul S, Lindestam Arlehamn CS, Scriba TJ, Dillon MB, Oseroff C, Hinz D, et al. Development and validation of a broad scheme for prediction of HLA class II restricted T cell epitopes. J Immunol Methods. 2015;422:28-34.

56. Lamonaca V, Missale G, Urbani S, Pilli M, Boni C, Mori C, et al. Conserved hepatitis $\mathrm{C}$ virus sequences are highly immunogenic for CD4(+) T cells: implications for vaccine development. Hepatology. 1999;30(4):1088-98.

57. Ferrari C, Bertoletti A, Penna A, Cavalli A, Valli A, Missale G, et al. Identification of immunodominant $\mathrm{T}$ cell epitopes of the hepatitis B virus nucleocapsid antigen. J Clin Invest. 1991;88(1):214-22.

58. Panina-Bordignon P, Tan A, Termijtelen A, Demotz S, Corradin G, Lanzavecchia A. Universally immunogenic T cell epitopes: promiscuous binding to human MHC class II and promiscuous recognition by T cells. Eur J Immunol. 1989;19(12):2237-42.

59. Berzofsky JA, Pendleton CD, Clerici M, Ahlers J, Lucey DR, Putney SD, et al. Construction of peptides encompassing multideterminant clusters of human immunodeficiency virus envelope to induce in vitro $\mathrm{T}$ cell responses in mice and humans of multiple MHC types. J Clin Invest. 1991;88(3):876-84.

60. Worgall S. 40 years on: have we finally got a vaccine for Pseudomonas aeruginosa? Future Microbiol. 2012;7(12):1333-5. 